\title{
A IMPORTÂNCIA DA BARRAGEM CAJARANA GARANHUNS- PE PARA O DISTRITO DE SÃO PEDRO
}

\author{
Lídia Vilela de Morais ${ }^{1}$
}

Maria Betânia M. Amador ${ }^{2}$

RESUMO: A Barragem Cajarana está localizada no Agreste pernambucano, Região Nordeste do Brasil. Tendo a mesma uma grande importância para o Distrito de São Pedro Garanhuns -PE. A noção de qualidade da água pode variar muito dependendo principalmente do uso a ser feito dela. A poluição tem sido uma fonte crescente de problemas sócio-econômicos e ambientais, impedindo o uso e consumo de suas águas de uma forma saudável pelos indivíduos que necessitam dessas águas para sua sobrevivência, visto que a região enfrenta um déficit hídrico devido as condições climáticas - geográficas e a falta de educação ambiental é um fator que só agrava a situação. A Barragem Cajarana é usada e caracterizada como a única fonte de abastecimento do Distrito, além de proporcionar fontes de renda para alguns moradores que trabalham em atividades agropecuárias desenvolvidas no seu entorno. Assim esse trabalho sob o ponto de vista socioambiental, teve a finalidade de tornar público e saliente à necessidade de preservação de recursos naturais. A metodologia utilizada pautou-se em pesquisa bibliográfica, sobre temas como uso e preservação dos recursos naturais, além visitas a campo, onde foi aplicado questionários, buscaram-se também análises químicas de alguns parâmetros da água para uma melhor compreensão de sua qualidade.

Palavras-chave: Represa Cajarana. Sócio ambiental. São Pedro

\footnotetext{
${ }^{1}$ GRADUADA Licenciatura em Geografia. UPE/Campus Garanhuns. vilelademoraeslidia@yahoo.com.br

${ }^{2}$ Prof ${ }^{\underline{a}}$ Adjunta da UPE/Campus Garanhuns. Pesquisadora líder do Grupo de Estudos Sistêmicos do Semiárido do Nordeste - GESSANE.
} 


\section{INTRODUÇÃO}

A água constitui um recurso natural indispensável, para a manutenção da vida, para o funcionamento dos processos dinâmicos do planeta e também para suporte das atividades humanas.

Os mais remotos filósofos gregos já alegavam que tudo provém da água. A ciência, por sua vez, tem comprovado que a vida se originou na água e que ela estabelece a matéria fundamental em todos os corpos vivos. Por mais que tentamos não conseguimos imaginar um tipo de vida em sociedade que dispense o uso da água: água para beber e para cozinhar; para a higiene do lar e das cidades; para uso industrial, irrigação das plantações, geração de energia, navegação, lavagem e transporte de detritos, entre outros.

Assim sendo a água constitui fator de grande importância na constituição do mundo em que vivemos. No clima, permite a manutenção de temperaturas amenas e variações não muito acentuada sendo também a responsável pela formação da maior parte das rochas sedimentares. Além disso, constitui componente indispensável à existência da vida em todas as suas formas. BRANCO (2003, p.9).

No entanto a água no meio urbano tem vários aspectos. O primeiro, que qualquer pessoa tem sempre na mente, é o do abastecimento da população. Contudo vários outros aspectos devem ser considerados, principalmente com o aumento e a densificação populacional que o mundo vem sofrendo nos últimos tempos.

Dessa maneira, o Distrito de São Pedro possui uma grande relação de dependência com a Barragem Cajarana (Figura 1) sendo a mesma a única fonte de abastecimento da comunidade, construída em 1990 com o intuito de eliminar os problemas de fornecimento d'água, essa dependência está relacionada tanto ao abastecimento quanto as atividades que são desenvolvidas no entorno da Barragem, como por exemplo, a agricultura e pecuária, gerando fontes de renda para as pessoas que trabalham no local.

Considerando-se o índice de poluição Samuel Murgel (2003 p. 61), afirma que potável "significa que se pode beber". Para ser ingerida é essencial que a água não contenha elementos nocivos à saúde. Mas não é só isso. Para ser bebida pelo ser 
humano e utilizada no preparo de alimentos e na higiene corporal, é necessário que a água atenda a certos requisitos estéticos, isto é, que não possua sabor, odor ou aparência desagradável.

Neste caso, deve-se considerar que existe um padrão da qualidade da água para o consumo das comunidades humanas, pode-se então constatar que o homem sempre teve a preocupação em relação à água que bebe, devendo a mesma ser cristalina e transparente.

\section{LOCALIZAÇÃO DA ÁREA}

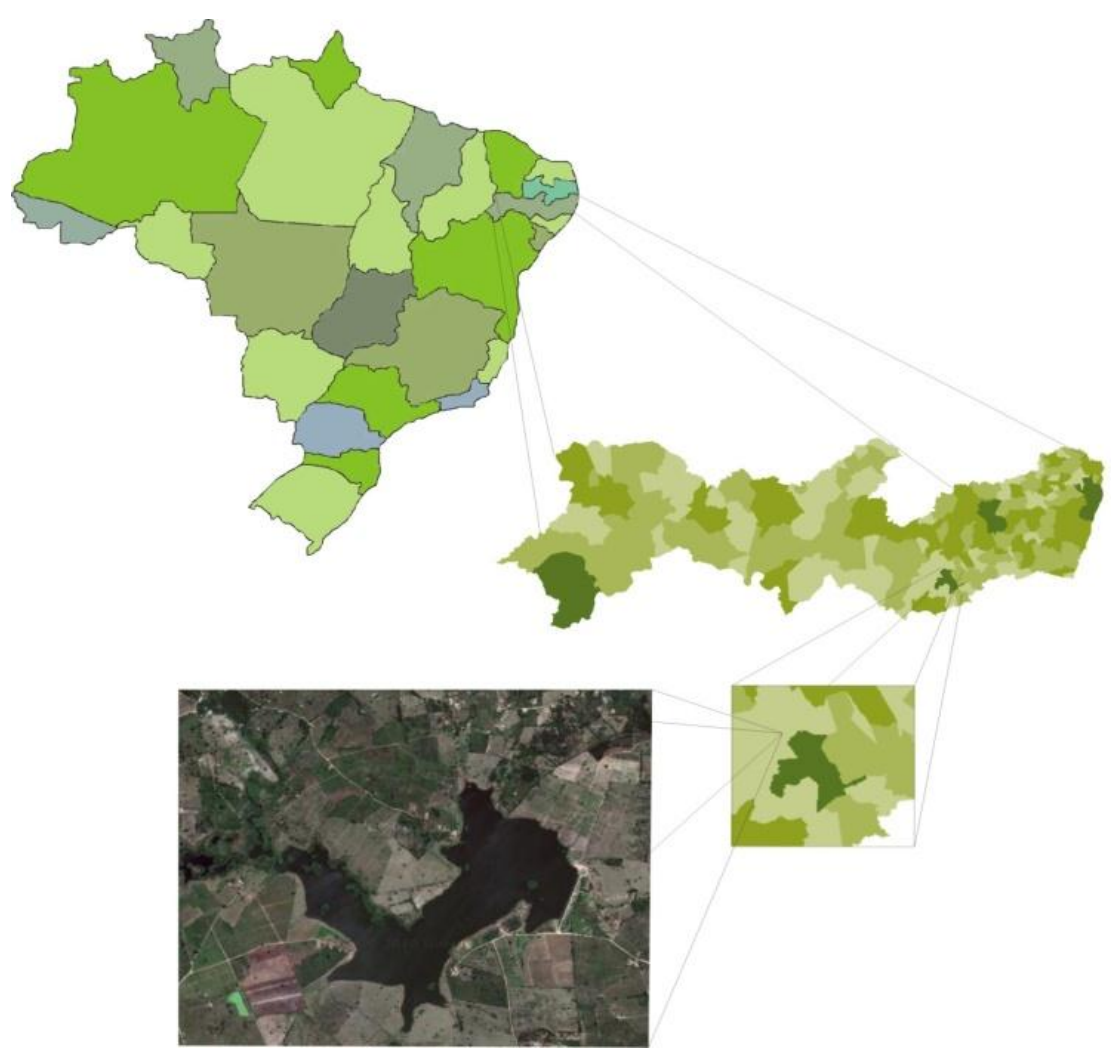

Figura 1: Localização da Barragem Cajarana no Distrito de São Pedro, Garanhuns/PE

O Distrito de São Pedro está inserido na Microrregião de Garanhuns e Mesorregião do Agreste Pernambucano. Segundo Rebouças (2006 p.483), o semiárido do Nordeste caracteriza-se por sua cobertura vegetal rasteira denominada caatinga, por apresentar 
embasamento cristalino predominante, solos agrícolas geralmente rasos e evapotranspiração acima de 2000 mm, além de evidenciar um intenso déficit de recursos hídricos, principalmente em se tratando de água potável.

Desse modo, a noção pragmática de semiárido tem sido a região onde acontecem as secas prolongadas que vai desde a falta de precipitação e deficiência de umidade no solo agrícola, quebra de produção agropecuária entre outros. No entanto, tomando-se por base esse contexto, deve-se ressaltar que a Barragem Cajarana tem sido a única fonte de abastecimento da Comunidade de São Pedro. Nesse sentido existe padrão de qualidade da água de abastecimento para o consumo humano. Segundo BRANCO (2003 p.60)

Para não ser nociva à saúde, a água não pode conter substâncias tóxicas e organismos patogênicos. Por isso, a que é distribuída a uma cidade deve ser diariamente analisada em vários pontos do sistema de distribuição por meio da colheita de amostras padronizadas que são encaminhadas a laboratórios especializados.

Em momentos de saída a campo relatou-se em questionário a fala de um senhor entrevistado onde alega que o nível d'água está baixando cada vez mais e isso é assustador porque muitos moradores trabalham na colheita de tomates, repolho e pimentão que é cultivado no entorno da Barragem, e ainda afirma que é a sorte desses moradores, senão estariam passando fome por não terem outra atividade a desenvolver, e que essas atividades desenvolvidas no entorno da Barragem é à base de sustentação da feira que acontece uma vez por semana no Distrito.

Neste caso o plantio de tomates e hortaliças foi proibido pelo IPA, instituto de pesquisa agropecuária, mas não à atendimento as suas exigências por questões políticas, pelo fato de alguns moradores tirarem seu sustento dessas atividades, ou seja o Distrito não oferece outras atividades que seus moradores possam desenvolver gerando assim fonte de renda para a população. 

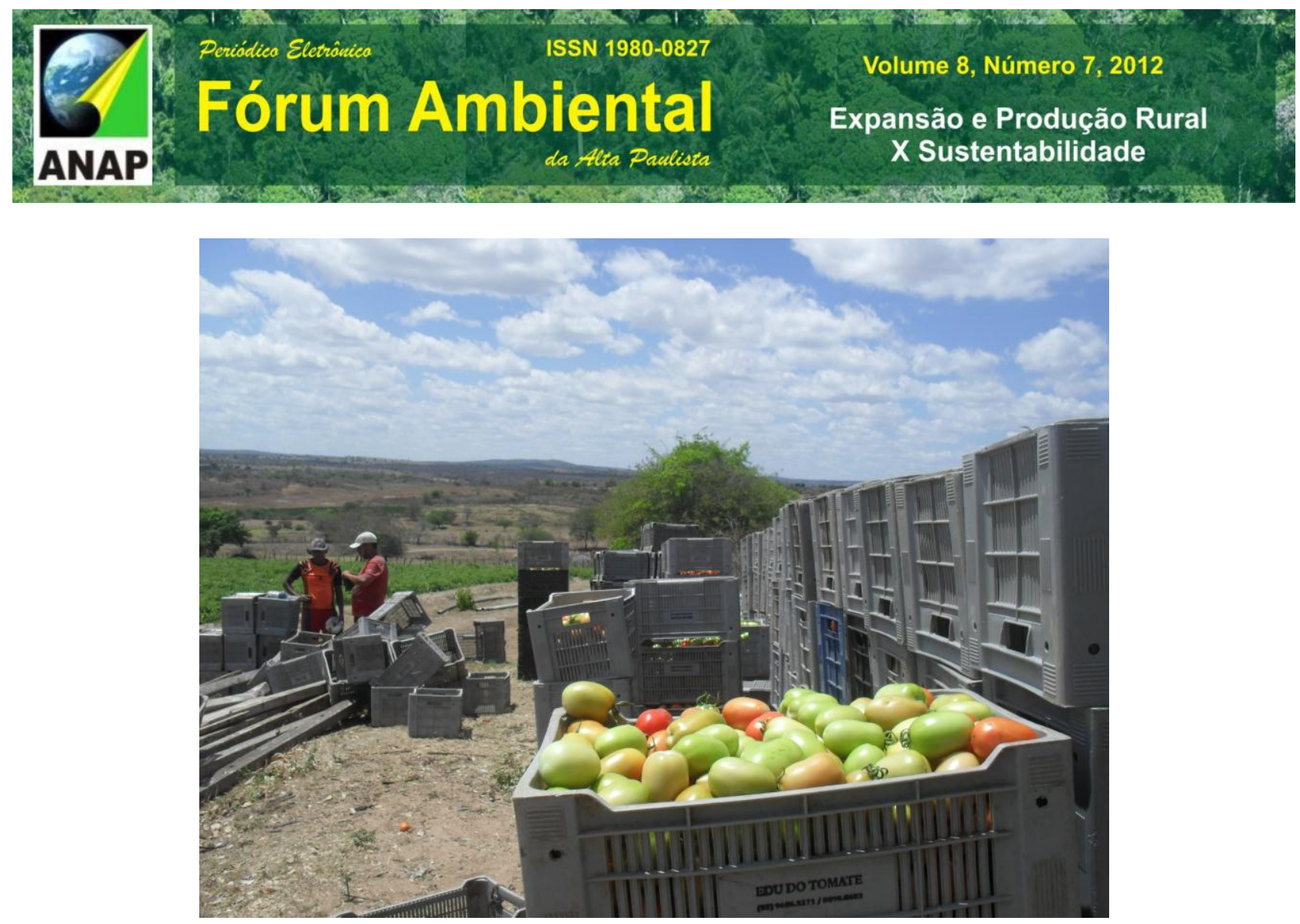

Figura 2: Armazenamento de hortaliças para transporte Fonte: Pesquisa de campo, ago. 2011. Foto de Vilela M. L.

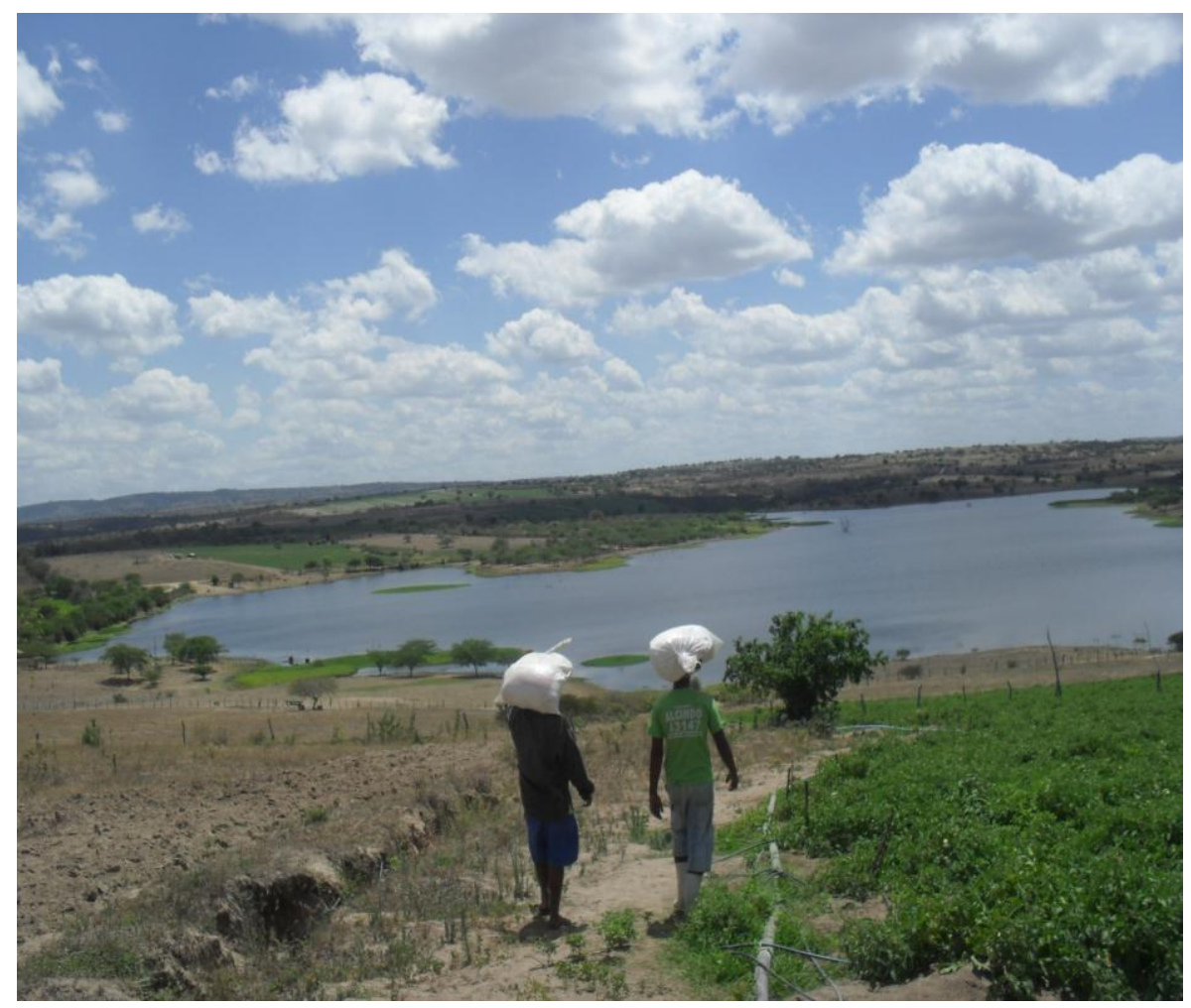

Figura 3: Atividade desenvolvida no entorno da Barragem Cajarana Fonte: Pesquisa de campo, agosto. 2012.Foto de Morais, L. V. 
Outra senhora, também entrevistada, relata que boa parte da comunidade tem comprado água da sede municipal, o seja, Garanhuns para usar no consumo doméstico (cozinhar e beber), pois além de pagar a taxa emitida pela COMPESA (Companhia Pernambucana de Saneamento), ainda tem que comprar para consumir na cozinha, conta ainda que a resistência do chuveiro elétrico queima com aproximadamente um mês, devido à salinidade da água.

Nesse sentido, cabe ressaltar que dependemos da qualidade da água para manter nossa saúde. Segundo DIAS (2004 p. 317):

O estado de abastecimento de água e saneamento nos países em desenvolvimento é caótico. Cerca de um bilhão e duzentos milhões de pessoas não têm acesso à água potável, e um bilhão e oitocentos milhões não têm acesso a serviços de saneamento.

Desse modo, o nível de desenvolvimento de um povo é analisado pela qualidade da água e dos serviços de saneamento que Ihes são proporcionados. A água considerada um recurso mineral que existe no mundo há mais de três bilhões de anos, responsável pela continuidade da vida na terra, continua sendo um fator limitante e decisivo para a biota.

No entanto, a água não pode conter substâncias tóxicas e mecanismos patogênicos caso contrário, pode ser prejudicial à saúde pública. Neste caso, a água que é distribuída a uma cidade deve ser avaliada em diversos pontos do sistema de distribuição, através de amostras que são conduzidas a laboratórios especializados. Como afirma BRANCO (2003 p. 61):

\footnotetext{
Há uma extensa lista de substâncias que, embora possam estar presentes na água, não devem ultrapassar certos limites de concentração, pois podem tornar-se nocivas pelo seu uso continuado. Essa lista de substâncias tende a ser modificada e aumentada à medida que novos compostos químicos são inventados e utilizados pelo homem em sua indústria, ou que novas descobertas são feitas pela ciência a respeito de suas propriedades fisiológicas.
}

Nesse sentido, o COMANA estabelece que seja feita a analise química ou exames laboratoriais da água a cada seis meses para manter um controle de substâncias existentes dentro do padrão exigido. De acordo com a COMPESA, um recurso hídrico deve ser analisado e estudado durante cinco anos para que suas águas possam ser distribuídas para o consumo humano, contudo nem sempre é isso que acontece. No caso 
da Barragem Cajarana, foi analisada apenas por dois anos, segundo a COMPESA isso ocorreu devido ao déficit de recursos hídricos que a região apresentava e ainda apresenta.

As tabelas abaixo evidenciam o padrão da qualidade da água estabelecido pelo COMANA, são exames químicos da água no seu estado bruto. Este procedimento serve para que a estação de tratamento tenha conhecimento de quais substâncias químicas irá usar no sistema de tratamento da água. Esses exames são realizados no intervalo de seis meses, avaliando a água no período das chuvas e da estiagem. Assim, há algumas diferenças de um exame para outro.

No período das chuvas algumas substâncias tendem a aumentar devido ao carregamento da água do solo para a Barragem. Na (tabela 1), o exame químico avalia alguns parâmetros d'água no período de estiagem da região, realizado em abril de dois mil e doze. Já na (tabela 2), a análise foi realizada no período seguido das chuvas, seis meses após o primeiro exame, deixando evidente o aumento dos compostos químicos carreados dos solos para as águas.

TABELA 1: Certificado de Análise Físico-Química da Água da Barragem Cajarana.

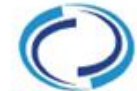

Companhia Pernambucana de Saneamento

Página: 1

Data $13 / 04 / 2012$

compeSa SGCQ - Sistema de Gestão de Controle da Qualidade

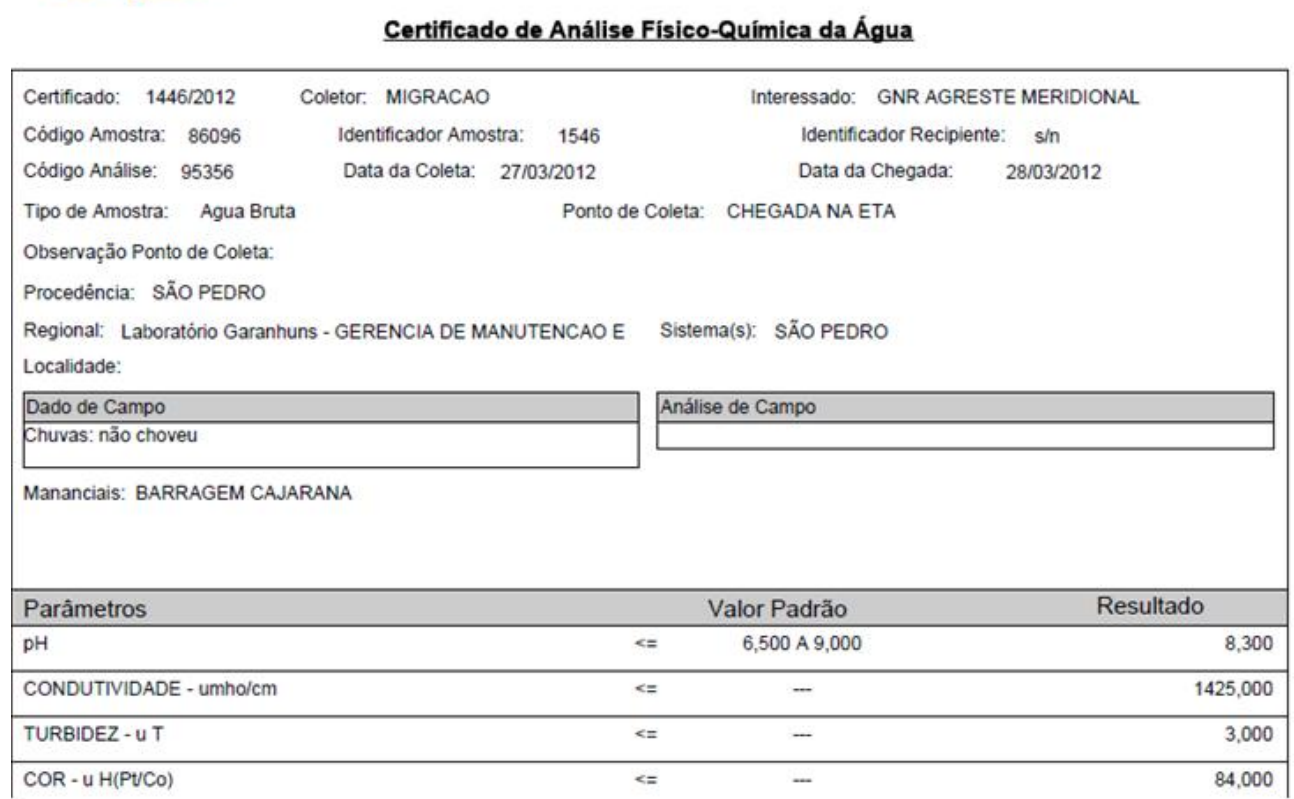




\section{Expansão e Produção Rural}

$X$ Sustentabilidade

\begin{tabular}{|c|c|c|c|}
\hline ALCALINIDADE - mg/L $\mathrm{CaCO} 3$ & $<=$ & - & 169,000 \\
\hline DUREZA TOTAL - $\mathrm{mg} / \mathrm{L} \mathrm{CaCO} 3$ & & & 294,700 \\
\hline CÁLCIO - mg/L de Ca & $<=$ & - & 51,400 \\
\hline MAGNÉSIO - mg/L de Mg & $<=$ & - & 40,390 \\
\hline SÓDIO - mg/L de Na & $<=$ & - & 192,310 \\
\hline POTÁSSIO - mg/L de K & $<=$ & - & 30,340 \\
\hline CLORETOS - mg/L de Cl & $<=$ & 250,000 & 393,400 \\
\hline SULFATO - mg/L SO4 & $<=$ & 250,000 & 1,000 \\
\hline N. AMONIACAL - mg/L de N & $<=$ & 1,00 & 0,100 \\
\hline N. NITRITO - mg/L de N & $<=$ & 1,000 & Ausente \\
\hline N. NITRATO - mg/L de N & $<=$ & 10,000 & 1,400 \\
\hline FOSFATO TOTAL - mg/L de P & $<=$ & 0,030 & 0,091 \\
\hline CARBONATO - $\mathrm{mg} / \mathrm{L}$ de $\mathrm{CO} 3$ & $<=$ & - & 0,000 \\
\hline FLUORETOS - mg/L de F & $<=$ & 1,400 & 0,018 \\
\hline \multicolumn{4}{|l|}{ Observação: } \\
\hline \multicolumn{4}{|c|}{$\begin{array}{l}\text { Valor padrão conforme estabelecido pela Resolução CONAMA nْ } 357 / 05 \text { para água classe 2, destinada ao abastecimento doméstico após } \\
\text { tratamento convencional. }\end{array}$} \\
\hline
\end{tabular}

Fonte: COMPESA, Garanhuns, PE, out. 2012.

TABELA 2:Certificado de Análise Físico-Química da Água da Barragem Cajarana.<smiles>c1ccccc1</smiles>

Companhia Pernambucana de Saneamento

compeSa SGCQ - Sistema de Gestão de Controle da Qualidade

\section{Certificado de Análise Físico-Química da Água}

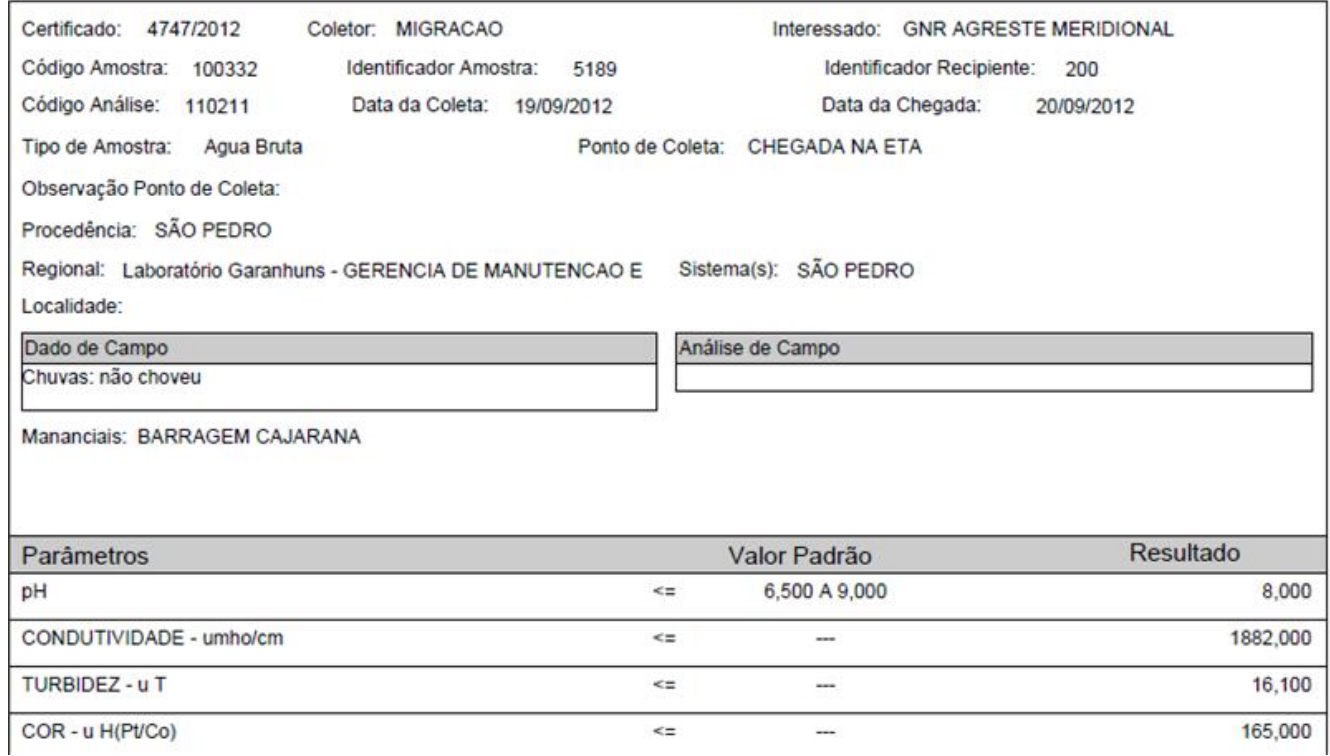




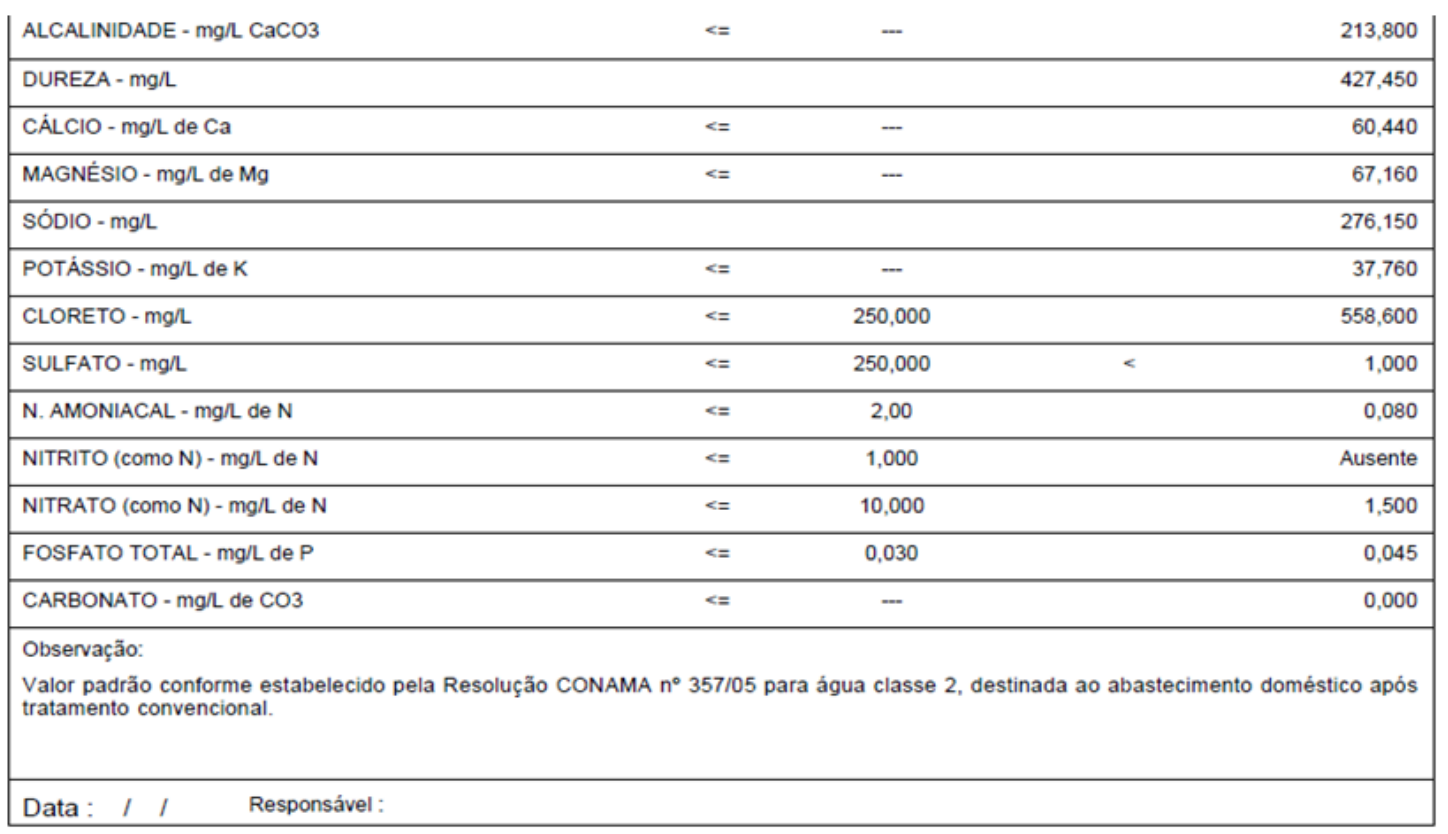

Fonte: COMPESA, Garanhuns, PE, out. 2012.

\section{PARÂMETROS}

A condutividade ocorre a partir do cloreto e do sódio, ou seja, através dos sais em geral, dissolvidos na água. Na segunda tabela analisada este parâmetro tem aumentado em consequência das chuvas que carregam os sais existentes no solo para dentro do espelho d'água aumentando, assim, o teor de salinidade. Cabe ressaltar que existe o cultivo de hortaliças no entorno da Barragem, onde são usadas sustâncias químicas que podem aumentar o teor de salinidade ao mesmo tempo em que são carreados. Mas, a COMPESA não afirma que este fato contribui com o aumento dos sais, pois o cultivo foi proibido pelo IPA (Instituto de Pesquisa Agropecuária), não havendo atendimento às exigências por motivos políticos.

A dureza total da água ocorre a partir da hidroxila, carbonatos e bicarbonatos, que estão relacionados ao poder de saponificação. Assim, pode-se constatar na fala da entrevistada, quando citou que a água não servia para lavar roupas.

Já a cor origina-se das substâncias dissolvidas e neste caso, refere-se ao ferro e ao manganês que, segundo entrevista com a analista química da COMPESA encontra-se dentro do limite pré-estabelecido como satisfatório. 
A turbidez da água, por sua vez, está relacionada com as partículas em suspensão que, no caso considerado, não é alta. Já o cloreto é bastante alto e, só pode ser retirado através da dessalinização da água. Nesse caso específico, a COMPESA ainda não possui equipamentos na região para tal tratamento. Neste sentido, observou-se que nos dados das tabelas este parâmetro está fora do padrão exigido pelo COMANA, ou seja, a água é mais que salobra, é salgada e está fora do padrão para o consumo humano.

O nitrato está ligado à poluição ou as substâncias patogênicas que neste caso está dentro, também, do limite satisfatório.

\section{CONCLUSÃO}

Após esse trabalho conclui-se que, de fato, a população do distrito em pauta como um todo, está usando água sem qualidade em termos dos teores de salinidade para o consumo humano. Embora haja fiscalização e controle de poluição pelos órgãos competentes, percebe-se que o componente político é mais forte e soberano, pois, como há muitos trabalhadores na área e dependentes dos plantios comerciais de tomates $\mathrm{e}$ outras hortaliças, deixa-se que se continue usando agrotóxicos, os quais contribuem significativamente com a deposição de sais no solo, além do processo de carreamento de sedimentos mais sais para dentro da barragem. A preocupação, então, dos políticos é deixar como está para que não haja perda de votos dos moradores que dependem dessa atividade. Vale salientar, ainda, que aqueles que não vivem diretamente das atividades do campo, mas vivem no distrito reclamam dessa qualidade da água e compram a mesma na sede municipal.

\section{AGRADECIMENTOS}

Agradecemos a colaboração da Engenheira Maisa Gonçalves Costa, Mestre em Engenharia Química pela Universidade Federal de Pernambuco e funcionária da COMPESA- Garanhuns, PE pelos dados sobre os parâmetros da água da represa Cajarana, Distrito de São Pedro, os quais foram de suma importância para os trabalhos aqui desenvolvidos. 


\section{REFERÊNCIAS}

DIAS, Genebaldo Freire. Educação ambiental: Princípios e práticas. 9. ed. São Paulo: Gaia, 2004.

DORST, Jean. Antes que a natureza morra: por uma ecologia política. Tradução Rita Buongermino. São Paulo: Edgard Blucher, 1973.

MORAIS, Lídia Vilela de. Uso do solo no entorno na represa Cajarana no Distrito de São Pedro no município de Garanhuns - PE. Universidade de Pernambuco - Campus Garanhuns, 2011. (Monografia) p 42.

MORAIS, Lídia Vilela de; AMADOR,Maria Betânia Moreira. Uso da Terra no entorno da Represa Cajarana no Distrito de São Pedro em Garanhuns - PE. XII Fórum Ambiental da Alta Paulista 2011

REBOUÇAS, A.C.; BRAGA, B.; TUNDISI, J. G. (Orgs.) Águas Doces no Brasil: capital ecológico, uso e conservação. 3. ed. São Paulo: Escrituras, 2006.

REBOUÇAS, Aldo da Cunha. Uso inteligente da água. São Paulo: Escrituras. Editora, 2004.

SAMUEL M. B. Água: origem, uso e preservação. São Paulo: Moderna, 1993. 